\title{
Anabases
}

ANABASES Traditions et réceptions de l'Antiquité

16 | 2012

Varia

\section{Annick FENET, Documents d'archéologie militante. La mission Foucher en Afghanistan (1922-1925)}

\section{Corinne Bonnet}

\section{OpenEdition}

\section{Journals}

Édition électronique

URL : http://journals.openedition.org/anabases/4015

DOI : 10.4000/anabases.4015

ISSN : 2256-9421

\section{Éditeur}

E.R.A.S.M.E.

\section{Édition imprimée}

Date de publication : 1 octobre 2012

Pagination : 306-308

ISSN : 1774-4296

\section{Référence électronique}

Corinne Bonnet, « Annick FENET, Documents d'archéologie militante. La mission Foucher en Afghanistan (1922-1925) ", Anabases [En ligne], 16 | 2012, mis en ligne le 01 octobre 2012, consulté le 22 septembre 2020. URL : http://journals.openedition.org/anabases/4015 ; DOI : https://doi.org/10.4000/anabases. 4015

Ce document a été généré automatiquement le 22 septembre 2020

(c) Anabases 


\section{Annick FENET, Documents d'archéologie militante. La mission Foucher en Afghanistan (1922-1925)}

\section{Corinne Bonnet}

\section{RÉFÉRENCE}

Annick FENET, Documents d'archéologie militante. La mission Foucher en Afghanistan (1922-1925), Mémoires de l'Académie des Inscriptions et Belles-Lettres, 42, Paris, Académie des Inscriptions et Belles-Lettres-De Boccard, 2010, 695 p + 37 ill. 122 euros / EAN 9782877542401.

1 En 2008, Annick Fenet avait proposé aux lecteurs d'Anabases un premier état des lieux des archives Foucher (cf. Anabases 7, 2008, p. 163-192) conservées à la Société Asiatique. Ce gisement magnifique et inédit, si bien valorisé par Annick Fenet, jette une singulière lumière sur la Délégation archéologique française en Afghanistan (la DAFA), ses missions, ses réseaux, ses enjeux, ainsi que sur la personnalité riche et attachante d'Alfred Foucher (1865-1952). Premier directeur de la DAFA suite à la signature de la Convention franco-afghane en 1922, Foucher a légué à Jean Filiozat un fonds d'archives exceptionnel pour l'histoire de l'orientalisme français. C'est sur la mission d'Afghanistan, entre 1922 et 1925, qu'Annick Fenet a centré son enquête, essentiellement épistolaire. Face à un fonds documentaire si prolifique, A. F. a fait des choix, à savoir 335 documents, éclairant une galerie de plus de 70 personnages, masculins et féminins, acteurs de l'aventure afghane à divers titres, qui permettent en définitive de se livrer à l'" autopsie " d'une mission archéologique. Les lettres, à michemin entre le domaine public et privé, renseignent, en effet, à la fois sur le caractère, le comportement, les espoirs et déceptions, bref la psychologie des personnages, sur les péripéties, les échecs, les réussites, les défis d'une entreprise scientifique hors du commun et, enfin, sur les pratiques, les techniques, les institutions et les objectifs 
scientifiques, y compris les rapports de fouilles et ouvrages de synthèse. C'est donc un «monde » que le magnifique livre d'Annick Fenet nous dévoile au fil des échanges. Un monde de voyages, d'explorations, mais aussi d'écriture puisque la plupart des éléments convergent vers le volume publié finalement par Foucher en 1942 La vieille route de l'Inde de Bactres à Taxila.

2 Dans l'ensemble documentaire envisagé (qui déborde largement, du point de vue chronologique, les trois ans et huit mois de la mission elle-même), contrairement à ce que l'on observe dans les archives de Franz Cumont, le volet actif de la correspondance est mieux représenté que le volet passif en raison des difficultés de communication avec la Perse, l'Afghanistan ou l'Inde, d'une part, grâce à la présence des «lettresbrouillons » rédigées et conservées par les Foucher, d'autre part. Madame Foucher, en effet, est un acteur majeur de l'aventure, et pas le moins intéressant! Annick Fenet, dans sa copieuse introduction qui constitue une véritable monographie (p.35-153), présente très bien l'univers affectif et scientifique des Foucher, avec en particulier la personnalité décisive d'Émile Senart (1847-1928), spécialiste non universitaire de la philologie et de l'épigraphie indiennes, le mentor de Foucher, mais aussi Philippe Berthelot (1866-1934), qui travaille au ministère des Affaires étrangères, sans oublier l'entourage académique qui rendit possible la mission d'Afghanistan et l'exploration archéologique du "mirage bactrien». Les lettres décrivant le déroulement de la mission, comme celles qu'échangèrent Cumont et Rostovtzeff au sujet des fouilles de Doura-Europos, permettent de sonder les méthodes, les outils, les pratiques d'une archéologie coloniale, soucieuse notamment d'alimenter les musées.

3 Annick Fenet met bien en perspective les événements de 1922-1925 par rapport à l'orientalisme français et à la carrière de Foucher, que l'exploration de l'Asie centrale tentait depuis les premières années du $\mathrm{Xx}^{\mathrm{e}}$ siècle. Elle nous permet de le suivre dans ses premiers pas à Kaboul, de le voir évoluer dans les milieux anglophones ou anglomanes, aux confins de l'Inde, ou d'appréhender sa conception forcément coloniale des populations afghanes... Comme le note Paul Bernard dans son introduction (p. 23), « il n'est aucune piste de recherche que l'auteur n'ait tenu au moins à sonder ». Par delà les lettres, elle explore fort bien la réception de la Mission en Afghanistan, dans des conférences («un tourbillon» qui retarda la publication de la synthèse de Foucher jusqu'en 1942 !), des communications, des articles dans les journaux, des publications scientifiques diverses. Foucher écrit sans se ménager pour communiquer sur les résultats des fouilles de Bactres, relayé par Senart notamment dans divers cercles, y compris dans le grand public curieux de comprendre cette étrange rencontre de cultures entre le monde grec et le monde afghan et indien.

Les lecteurs d'Anabases, intéressés par l'histoire des savoirs, par les pratiques et la sociabilité savantes, par la genèse des travaux scientifiques liront avec grand profit les 335 documents, variés, singuliers, passionnants, riches en contenus et en émotions. Pour autant que l'on puisse en juger sans connaître entièrement l'ensemble du fonds, le choix qui en a été fait par l'auteur semble extrêmement pertinent. Un appendice propose une annexe inédite de La vieille route de l'Inde, conservée en trois exemplaires dans le fonds Foucher, qui concerne l'historique de la Convention archéologique franco-afghane de 1922 et une série d'annexes très utiles (chronologie, liste des responsables politiques et scientifiques, inventaire des archives relatives à la création de la DAFA et à la mission Foucher). Une bibliographie et un index complètent une publication à tous égards exemplaire, passionnante de bout en bout. 


\section{AUTEURS}

\section{CORINNE BONNET}

Université de Toulouse (UTM)

corinne.bonnet@sfr.fr 